\title{
Article \\ Evaluation of Maturity and Odor Emissions in the Process of Combined Composting of Kitchen Waste and Garden Waste
}

\author{
Bangxi Zhang ${ }^{1,2}$, Feifei Fan ${ }^{2}$, Chao Guo ${ }^{1}$, Mingji Yu ${ }^{1}$, Mingcan Zhao ${ }^{1}$, Yuan Song ${ }^{1}$ and Yun Li ${ }^{1, *}$ (i) \\ 1 College of Resource and Environment, Qingdao Agricultural University, Qingdao 266109, China; \\ zbx@cau.edu.cn (B.Z.); chaoguo2018@stu.qau.edu.cn (C.G.); yumingji@stu.qau.edu.cn (M.Y.); \\ zhaomingcan@stu.qau.edu.cn (M.Z.); songyuan@stu.qau.edu.cn (Y.S.) \\ 2 Institute of Agricultural Resources and Environment, Guizhou Academy of Agricultural Sciences, \\ Guiyang 550006, China; 01fanfeifei@sina.com \\ * Correspondence: liyun2015@cau.edu.cn
}

check for updates

Citation: Zhang, B.; Fan, F.; Guo, C.; Yu, M.; Zhao, M.; Song, Y.; Li, Y. Evaluation of Maturity and Odor Emissions in the Process of Combined Composting of Kitchen Waste and Garden Waste. Appl. Sci. 2021, 11, 5500. https://doi.org/10.3390/ app11125500

Academic Editor: Rafael

López Núñez

Received: 8 May 2021

Accepted: 7 June 2021

Published: 14 June 2021

Publisher's Note: MDPI stays neutral with regard to jurisdictional claims in published maps and institutional affiliations.

Copyright: (c) 2021 by the authors. Licensee MDPI, Basel, Switzerland. This article is an open access article distributed under the terms and conditions of the Creative Commons Attribution (CC BY) license (https:// creativecommons.org/licenses/by/ $4.0 /)$.

\begin{abstract}
With the development of urbanization, kitchen waste and garden waste have become an important part of municipal solid waste (MSW), which is in urgent need of resource treatment. This study investigated the impacts of garden waste as auxiliary materials on maturity and odor emissions $\left(\mathrm{NH}_{3}\right.$ and $\left.\mathrm{H}_{2} \mathrm{~S}\right)$ during kitchen waste composting. The result showed that the combined composting product of kitchen waste and garden waste achieved the maturity effect, and the co-composting effect was better than that of separate composting of kitchen waste. Meanwhile, compared with the separate composting treatment of kitchen waste, the co-composting treatment of kitchen waste and garden waste can effectively reduce the cumulative emissions of $\mathrm{H}_{2} \mathrm{~S}$ by more than $85 \%$, and effectively reduce the cumulative emissions of $\mathrm{NH}_{3}$ by more than $75 \%$. This study provides a technical reference for the green fertilizer utilization of kitchen waste and garden waste.
\end{abstract}

Keywords: composting; kitchen waste; garden waste; maturity; odor emissions

\section{Introduction}

With the development of the economy, the continuous promotion of urbanization and the implementation of the new policy of waste classification, the resource treatment of municipal solid waste (MSW) had been widely carried out [1]. At present, kitchen waste $(\mathrm{KW})$ and garden waste $(\mathrm{GW})$ were the main MSW related to our life. In particular, first-tier cities, with a high degree of urbanization and high population density, result in large and concentrated production of KW and GW, which was in urgent need of resource treatment.

$\mathrm{KW}$ is difficult to place in landfill and incinerate directly because of its high organic matter and moisture content, ease of corruption, and low calorific value [2]. Composting can not only realize the harmlessness and reduction in $\mathrm{KW}$, but also produce organic fertilizer for agriculture, which is an effective way to treat KW [3]. However, due to the high moisture content and nitrogen content of the KW, composting the KW alone will produce a large amount of leachate and affect the composting process. Adding auxiliary materials to KW can not only adjust the moisture content and carbon-nitrogen ratio of the original materials, but also adjust the matrix porosity of the pile [4,5]. Therefore, the addition of auxiliary materials is conducive to ventilation and oxygen supply, ensuring rapid and efficient composting [6].

The addition of auxiliary (structure-forming) materials will not only affect the maturity of composting, but also affect the gas emission in the composting process [6]. At present, the main problem restricting the development of composting plants in China is the effect of the odor discharged in the composting process on the surrounding residents [7]. China has clearly defined limits for $\mathrm{NH}_{3}$ and $\mathrm{H}_{2} \mathrm{~S}$ emissions from composting plants. The most concentrated odors emitted during the composting of $\mathrm{KW}$ are $\mathrm{NH}_{3}$ and $\mathrm{H}_{2} \mathrm{~S}$ [8]. Among them, $\mathrm{H}_{2} \mathrm{~S}$ contributes the most to the concentration of odor [9]. The massive emission of 
$\mathrm{NH}_{3}$ and $\mathrm{H}_{2} \mathrm{~S}$ during the composting process not only produced odor pollution, but also reduced the nutrient content of the compost. The $\mathrm{NH}_{3}$ volatilized with the high temperature of the compost is the main reason for the loss of nitrogen during the composting process, accounting for about $20 \%$ to $60 \%$ of the total nitrogen [10].

Composting is an aerobic process in which bad aeration conditions can occur, being the main reason for the generation of $\mathrm{H}_{2} \mathrm{~S}$. About $9 \sim 43 \%$ of volatile sulfur compounds are lost in the form of $\mathrm{H}_{2} \mathrm{~S}$, which is characterized by a low detection odor threshold and high odor activity [11-13]. Therefore, serious odor pollution will occur even the concentration of $\mathrm{H}_{2} \mathrm{~S}$ is low. Adding auxiliary materials to the compost can improve the porosity of the pile, which is conducive to ventilation and oxygen supply, thereby reducing the emission of odor. Studies have shown that adding auxiliary materials to compost can reduce odor emission to varying degrees $[3,14]$.

Agricultural wastes such as straw and fungus chaff have been proven to have significant effects as auxiliary materials $[15,16]$. However, as a large number of KW is produced in cities, the transportation cost of agricultural waste as auxiliary materials is high. Meanwhile, the large amount of GW produced in cities together with KW has become a potential choice for composting.

Therefore, this research attempts to build a technology for reducing pollution and improving the maturity of the KW composting based on GW as an auxiliary material. Through the co-composting treatment of GW and KW, the maturity and gas emission of compost samples were measured. The feasibility of co-composting of GW and KW was verified by integrating the effects of pollution gas emission and product ripening in the composting process, in order to provide technical support for the green fertilizer utilization of kitchen waste.

\section{Materials and Methods}

\subsection{Composting Materials}

KW came from the waste collection and transfer station of Qingdao Agricultural University. KW consists of $45 \%$ vegetables, $29 \%$ fruits, $10 \%$ staples, $7 \%$ bones, eggshells and shells, $5 \%$ meat and $4 \%$ other food (wet weight). GW was collected from tree pruning and leaves in the campus of Qingdao Agricultural University. The initial moisture content of $\mathrm{KW}$ was about $70.6 \pm 2.2 \%$, and that of GW was about $4.9 \pm 1.4 \%$.

\subsection{Experimental Protocol}

Two treatments were designed in this study. In treatment 1 (T1), KW was used as a single material for composting. Additionally, in treatment 2 (T2), 15\% GW and 85\% $\mathrm{KW}$ were used as raw materials for composting. The proportion of raw materials in co-composting treatment is widely used for composting in practice [7]. The composting experiment was conducted for 21 days, with turning on the 3rd day and 7th day of the first week and weekly thereafter. About $150 \mathrm{~g}$ of solid samples were collected after each turning to analyze the physicochemical properties of the compost material. All testing of waste samples in this study was conducted in triplicate. Mean values and standard deviations of triplicate samples are shown in this study.

\subsection{Experimental Device}

A 20 L cylindrical self-made composting reactor (Figure 1) was used in this project. The reactor was surrounded by a foam layer to prevent heat loss. There are holes in the top of the lid to collect the gas released each day and to insert the temperature detector. An air pump aeration system was used to provide a continuous aeration rate of $0.4 \mathrm{~L} / \mathrm{kg}$ dry weight (DM) every minute to maintain aerobic compost. 


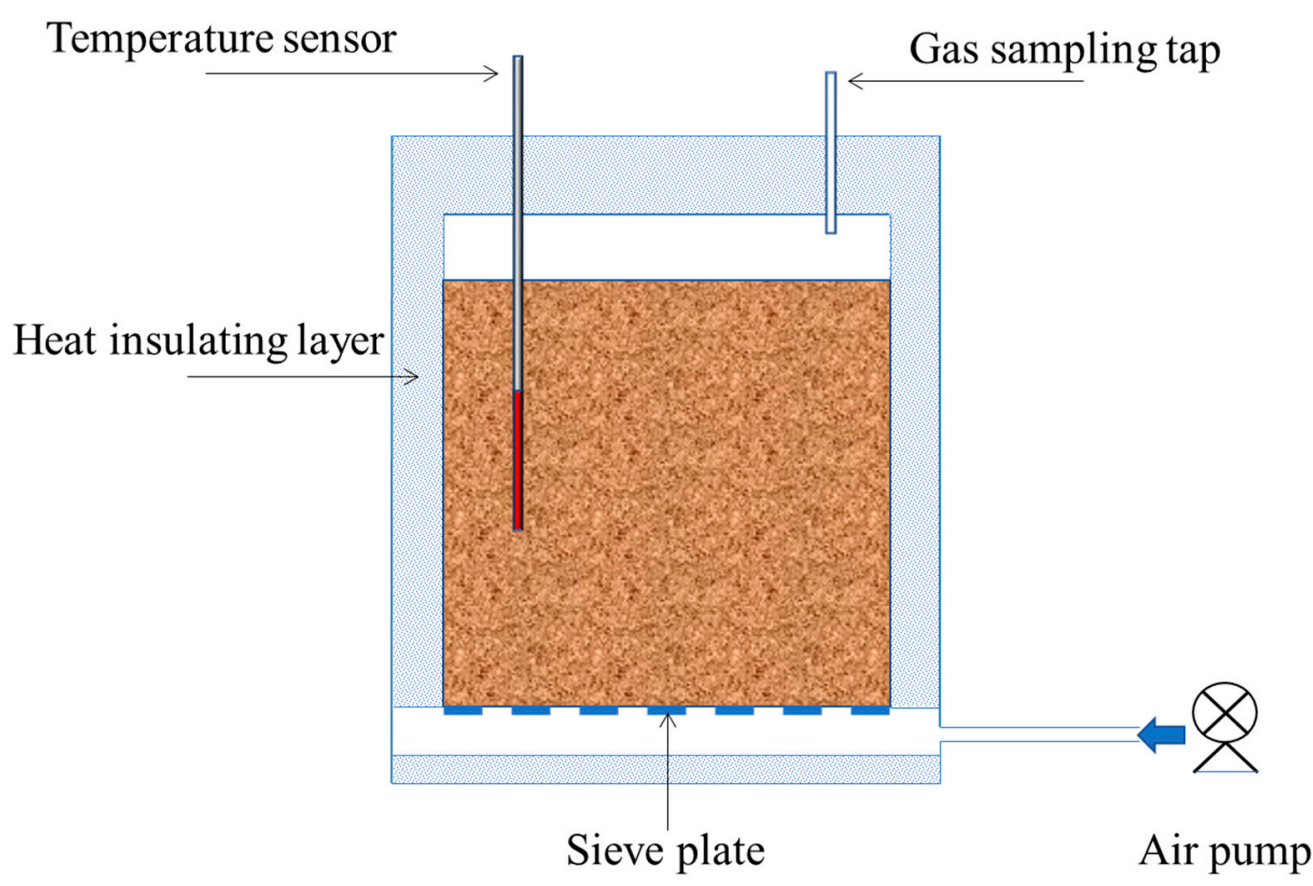

Figure 1. Schematic diagram of composting device.

\subsection{Analytic Methods}

The temperature of the reactor was read by a temperature sensor inserted into the reactor. $\mathrm{NH}_{3}$ was absorbed by boric acid with a mass fraction of $2 \%$, and then titrated with dilute sulfuric acid at a standard concentration. $\mathrm{H}_{2} \mathrm{~S}$ was determined using a portable biogas analyzer (BioGAS 5000).

Aqueous extract: $10.0 \mathrm{~g}$ of the frozen wet sample was weighed and added with deionized water at the ratio of 1:10 $(w / v)$ for extraction, oscillated for $30 \mathrm{~min}$, stood for $10 \mathrm{~min}$ and then filtered. The aqueous extract was taken to measure $\mathrm{pH}, \mathrm{EC}$ and the germination index (GI). The $\mathrm{pH}$ value was measured by an S-3C $\mathrm{pH}$ meter, and $\mathrm{EC}$ was measured by a DDS-11A conductivity meter. The GI value was determined by taking $5 \mathrm{~mL}$ of the aqueous extract above in a Petri dish with 10 seeds of Xinlimei radish covered with filter paper and incubating it in an incubator (SHP-250, Jinghong, Shanghai) at $(20 \pm 1)^{\circ} \mathrm{C}$ for $48 \mathrm{~h}$ in the dark. The root length and germination rate of the seeds were determined.

\section{Results and Discussion}

\subsection{Temperature}

During the whole composting process, temperatures of all the treated samples showed a similar change of rapid rise followed by a slow decrease (Figure 2). Due to the rapid degradation of organic matter in the compost material, a large amount of heat was generated [17], which had a good killing effect on Acaris eggs, Escherichia coli and other harmful pathogens. Previous studies proved that the thermophilic phase was reached faster due to the high decomposition of organic matter [18]. All treatments significantly increased to peak temperature (about $60^{\circ} \mathrm{C}$ ) on day 3 to day 4 , and then gradually decreased. Due to the redistribution of organic material and associated microorganisms by turning, the temperature of all treatments increased again on day 7 after turning. Over the next two weeks, the temperature followed a similar pattern of rising and then falling. At the end of the composting process, the temperature of all treatments was basically reduced to the ambient temperature, indicating that the compost had reached the ripening stage. 


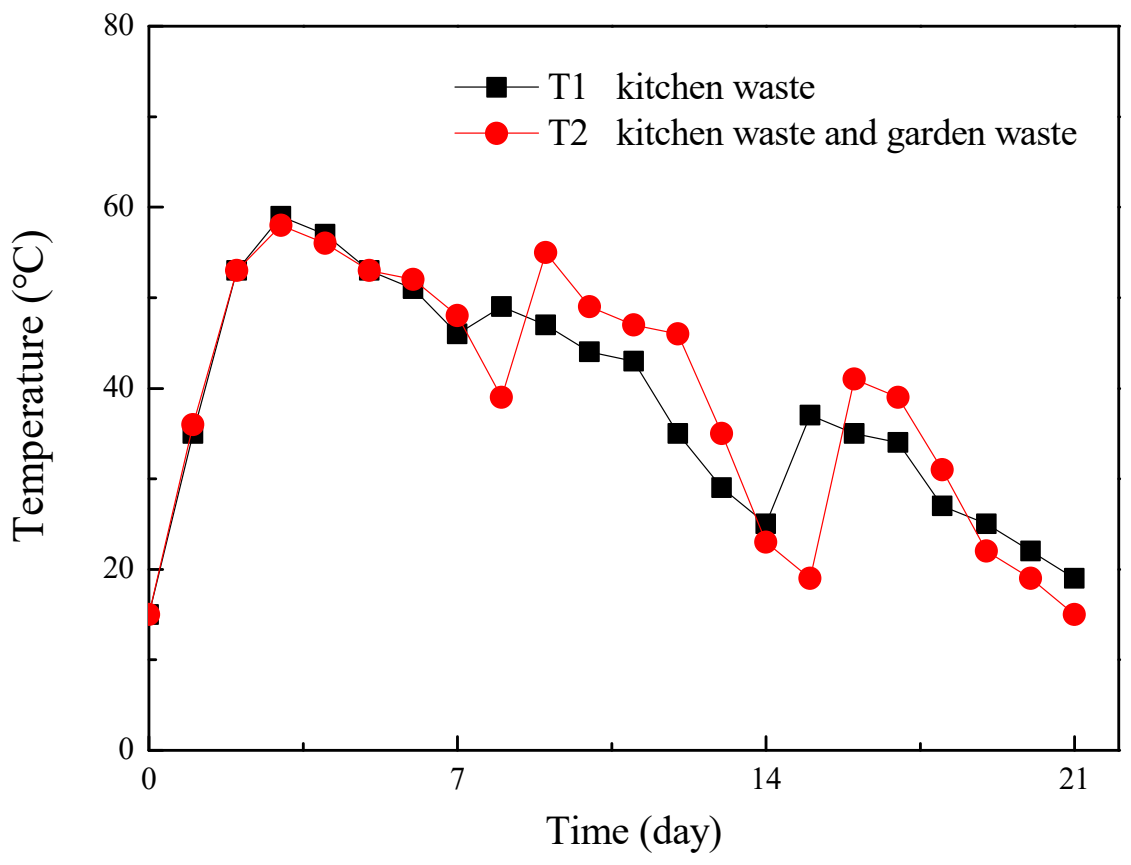

Figure 2. Evolution of temperature during composting.

\section{2. $p H$ and $E C$}

Different treatments had little influence on the $\mathrm{pH}$ value of the composting process. The $\mathrm{pH}$ value of all treatments increased significantly in the first week and finally maintained a stable stage of 7 to 8 (Figure 3). In the early stage of the co-composting of KW and $\mathrm{GW}$, the $\mathrm{pH}$ value of the materials was about 4 due to the acidification phenomenon of $\mathrm{KW}$ during the early storage. With a rapid biodegradation of easily degradable organic matter, small molecular organic acids were produced. With the rise of temperature, organic acid volatilization and mineralization of organic nitrogen will gradually increase $\mathrm{pH}$ [19]. In this study, due to the higher temperature and continuous aeration accelerating the generation of $\mathrm{NH}_{3}$ during the high temperature phase, organic acids volatilized and neutralized more thoroughly, resulting in the initial increase in substrate $\mathrm{pH}$. In the later stage of composting, the $\mathrm{pH}$ value of all treatments no longer increased in a large range due to the increased activity of nitrifying bacteria, which promoted the conversion of a small amount of $\mathrm{NH}_{4}{ }^{+}$ into $\mathrm{NO}_{3}{ }^{-}[20]$.

The EC value is an indicator of the soluble salt concentration in the aqueous extract of compost. Too high an EC value can cause toxic effects on crops [21,22]. The EC value for T1 treatment increased significantly in the first few days. This may be due to the rapid decomposition and mineralization of organic matter into small molecules, which increased the salt ion content. A downward trend was observed in the two subsequent treatments, which was due to the volatilization of organic acids and $\mathrm{NH}_{4}{ }^{+}$and humification $[23,24]$. By the end of composting, the EC values of all treatments were less than $3 \mathrm{mS} / \mathrm{cm}$, meeting the safe composting standard $(<4 \mathrm{mS} / \mathrm{cm})$. Compared with $\mathrm{T} 1$ treatment, $\mathrm{T} 2$ treatment can effectively reduce the EC value within 21 days of composting, which may be due to the improvement of physical and chemical properties of the composting materials, thus accelerating the humification process. 

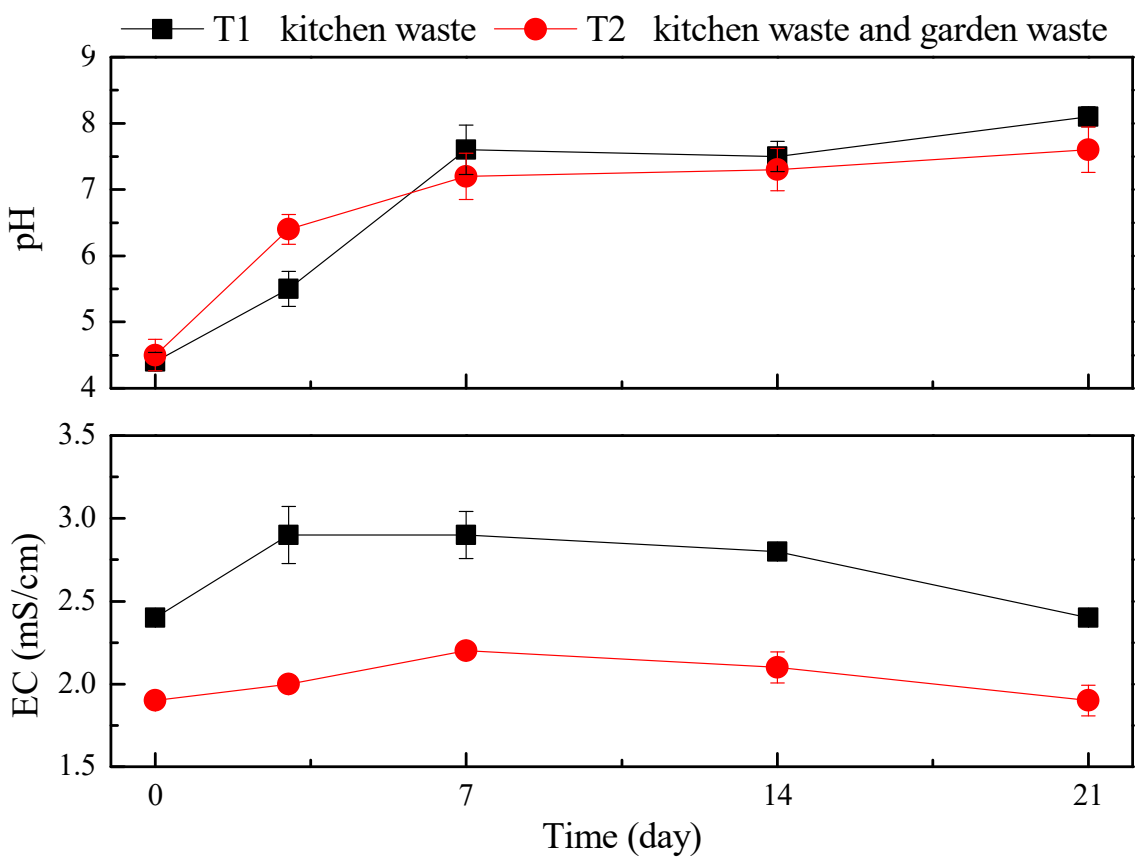

Figure 3. Evolution of $\mathrm{pH}$ and $\mathrm{EC}$ during composting.

\subsection{Germination Index (GI)}

The toxicity test of a water extract of compost on plant seeds is one of the important methods to test compost ripening degree [25]. The germination index (GI) of all treatments showed an increasing trend during the composting process (Figure 4). The elevated GI may be related to the removal of toxic substances (such as small molecular organic acids and $\mathrm{NH}_{4}{ }^{+}$) and the formation of humus. After 21 days of composting, GI was higher than $80 \%$ in T2 treatments, indicating that the composting product was free of plant toxicity and ripe [25]. Compared with the single composting treatment of KW (T1), the co-composting treatment of KW and GW (T2) had a higher GI value, and the products were less toxic to plants.

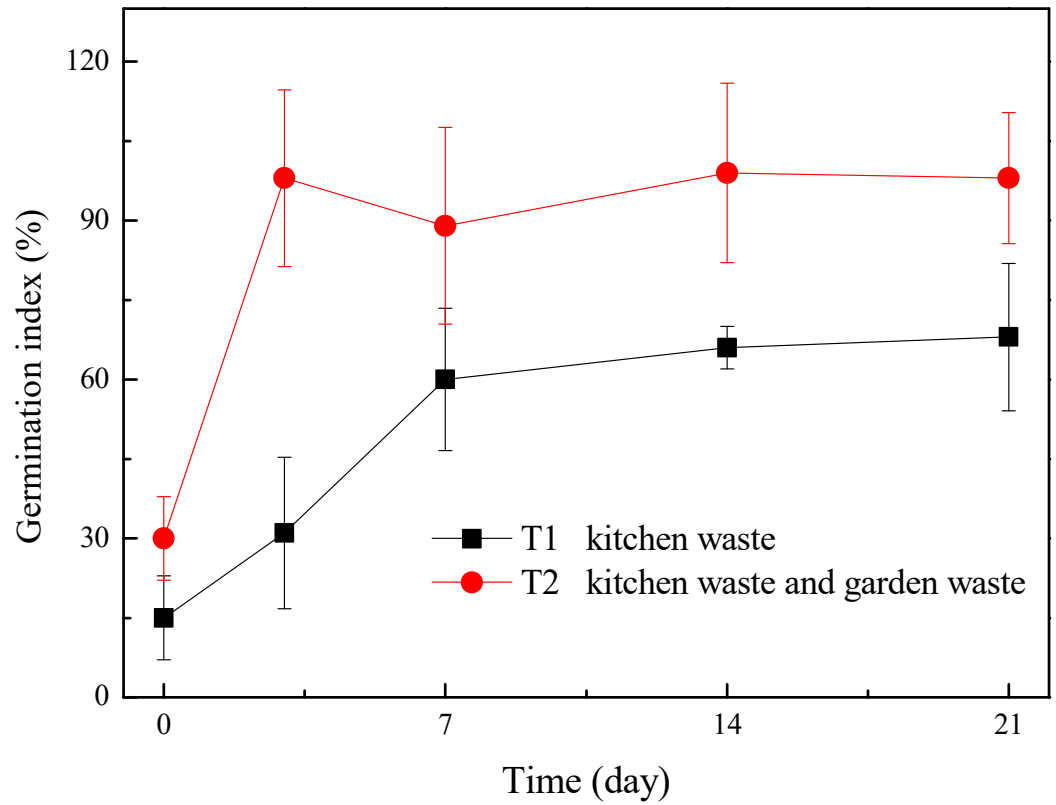

Figure 4. Evolution of germination index during composting. 


\section{4. $\mathrm{NH}_{3}$ Emission}

The $\mathrm{NH}_{3}$ emissions from all treatments mainly occurred during the high temperature period (Figure 5). This was mainly due to the strong mineralization of organic nitrogen into $\mathrm{NH}_{4}{ }^{+}$, which was further converted into $\mathrm{NH}_{3}$ under high temperature and alkaline conditions [10]. Therefore, $\mathrm{NH}_{3}$ emission peaks were observed for each treatment around day 7 of composting. As the temperature decreases, $\mathrm{NH}_{3}$ emissions then drop to a lower concentration. As mentioned above, turning can reactivate related microorganisms, restore biodegradation of organic matter, and regulate matrix porosity, thus facilitating the occurrence of $\mathrm{NH}_{3}$ re-discharge.
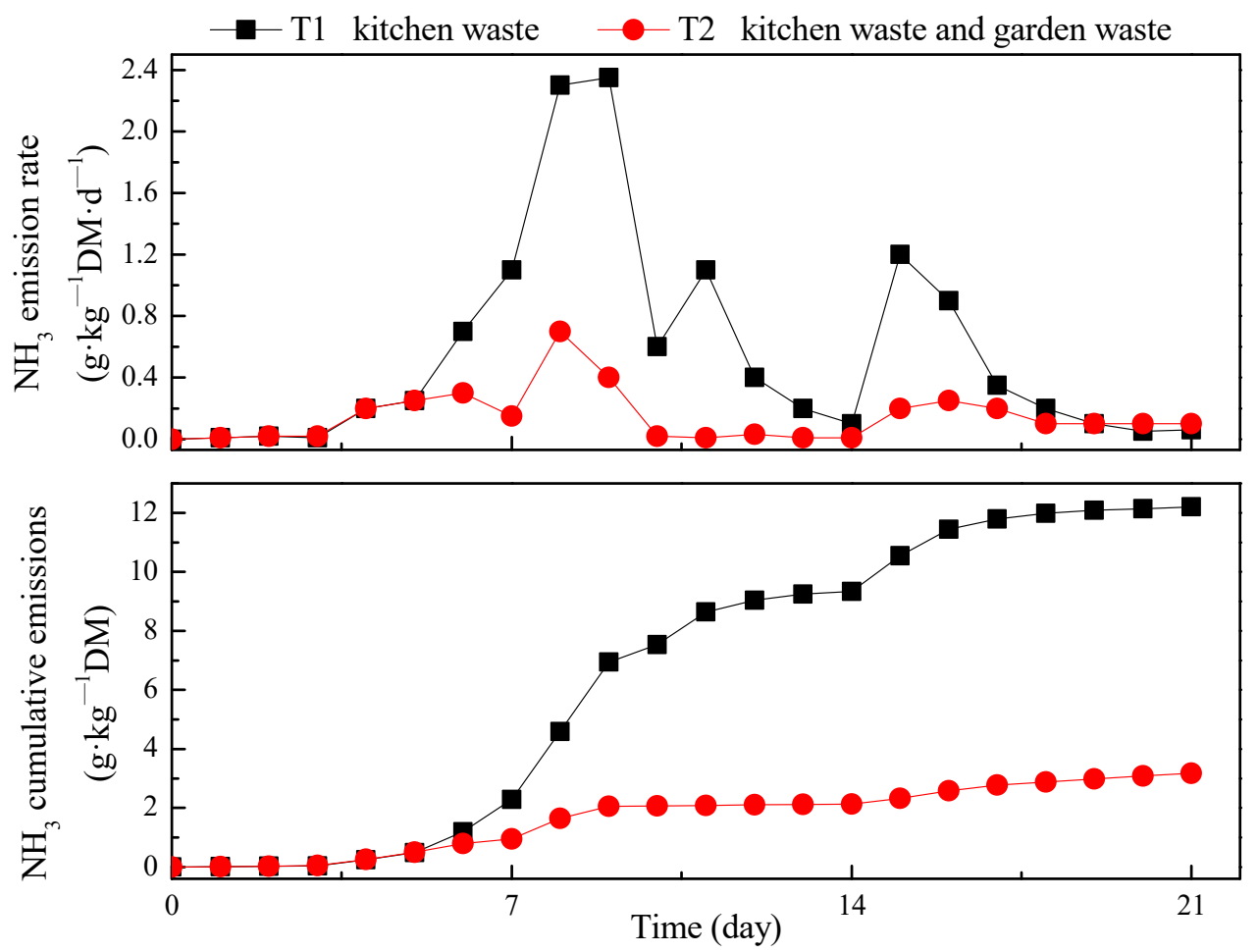

Figure 5. Evolution of $\mathrm{NH}_{3}$ during composting.

Compared with $\mathrm{T} 1$ treatment, $\mathrm{T} 2$ treatment can effectively reduce the cumulative $\mathrm{NH}_{3}$ emission by more than $75 \%$ (Figure 5). The main reason was that the addition of GW improved the $\mathrm{C} / \mathrm{N}$ ratio and biodegradation efficiency of the matrix in the composting process. In fact, T1 treatment inhibited biodegradation efficiency and prolonged the high temperature period (Figure 2), resulting in increased $\mathrm{NH}_{3}$ production after each turning of the heap to activate the compost matrix between day 7 and day 21 .

\section{5. $\mathrm{H}_{2} \mathrm{~S}$ Emission}

The $\mathrm{H}_{2} \mathrm{~S}$ emission rate of all treatments increased first and then decreased, and finally was basically close to zero (Figure 6). $\mathrm{H}_{2} \mathrm{~S}$ emission in the whole composting process mainly occurred in the first 7 days, accounting for about $80 \%$ of the total $\mathrm{H}_{2} \mathrm{~S}$ emission. Similar to the results of previous studies [26], $\mathrm{H}_{2} \mathrm{~S}$ emissions in the process of $\mathrm{KW}$ composting were mainly concentrated in the early stage, which may be mainly due to the intense microbial activities in the early stage of the reactor and the rapid temperature rise that consumes oxygen in the reactor, leading to the emergence of the local anaerobic environment. Other research also indicated that the main cause of generation of $\mathrm{H}_{2} \mathrm{~S}$ emission during composting was the lack of aeration [27]. Thus, the use of bulking agent provided porosity to the organic material to be composted. There is a peak of $\mathrm{H}_{2} \mathrm{~S}$ emissions after turning, which was consistent with the results of existing studies [9]. Compared with T1 treatment, T2 treatment can effectively reduce the cumulative $\mathrm{H}_{2} \mathrm{~S}$ emission by more than $85 \%$. The main 
reason was that the addition of GW improves the permeability of the matrix in the process of composting, improved the hypoxia condition in the material and inhibits the generation of $\mathrm{H}_{2} \mathrm{~S}$.
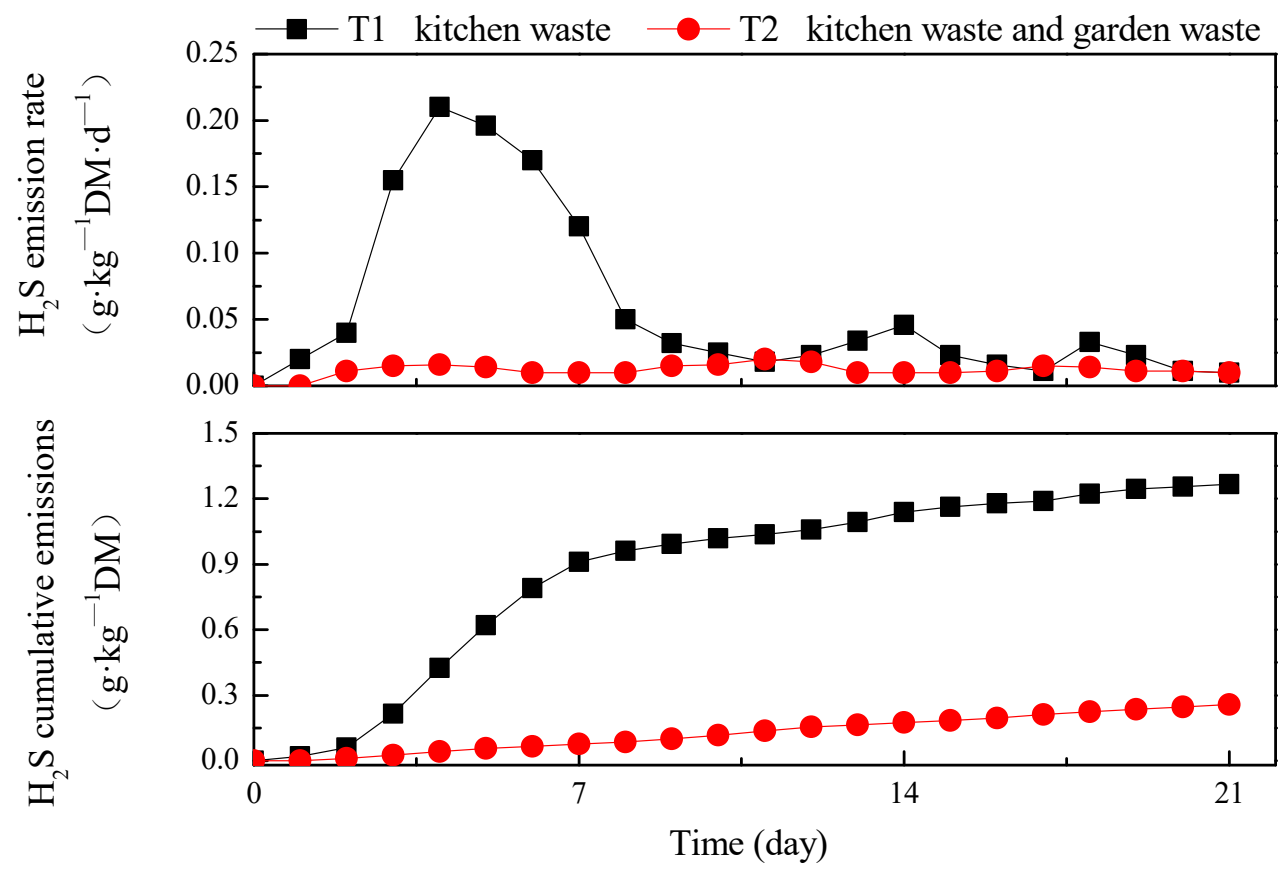

Figure 6. Evolution of $\mathrm{H}_{2} \mathrm{~S}$ during composting.

\section{Conclusions}

The co-composting of kitchen waste and garden waste can achieve the ripening effect, and the co-composting effect was better than the single composting treatment of kitchen waste. The $\mathrm{pH}$ and EC values of each treatment meet the safe application of organic fertilizer at the end of composting. GI was higher than $80 \%$ in co-composting treatment, indicating that the composting product was free of plant toxicity and ripe. Compared with the separate composting treatment of kitchen waste, the co-composting treatment of can effectively reduce the cumulative $\mathrm{H}_{2} \mathrm{~S}$ emission by more than $85 \%$, and effectively reduce the cumulative $\mathrm{NH}_{3}$ emission by more than $75 \%$.

Author Contributions: Data curation, B.Z. and F.F.; investigation, C.G., M.Y., M.Z. and Y.L.; methodology, C.G. and M.Y.; resources, Y.S.; supervision, Y.L.; writing—original draft, B.Z.; writing-review and editing, F.F. and Y.L. All authors have read and agreed to the published version of the manuscript.

Funding: This research was funded by "the Science and Technology Plan Project Foundation of Guizhou province, grant number 20182341 and 20191452" and "the High-level Talent Research Fund of Qingdao Agricultural University".

Institutional Review Board Statement: Not applicable.

Informed Consent Statement: Not applicable.

Data Availability Statement: Not applicable.

Conflicts of Interest: The authors declare no conflict of interest.

\section{References}

1. Hafid, H.; Rahman, N.; Shah, U.; Baharuddin, A.; Ariff, A. Feasibility of Using Kitchen Waste as Future Substrate for Bioethanol Production: A Review. Renew. Sustain. Energy Rev. 2017, 74, 671-686. [CrossRef]

2. Karimi, S.; Karimi, K. Efficient ethanol production from kitchen and garden wastes and biogas from the residues. J. Clean. Prod. 2018, 187, 37-45. [CrossRef] 
3. Yuan, J.; Yang, Q.; Zhang, Z.; Li, G.; Luo, W.; Zhang, D. Use of additive and pretreatment to control odors in municipal kitchen waste during aerobic composting. J. Environ. Sci. 2015, 37, 83-90. [CrossRef]

4. Zhu, N. Effect of low initial C/N ratio on aerobic composting of swine manure with rice straw. Bioresour. Technol. 2007, 98, 9-13. [CrossRef]

5. Wang, Z.; Gao, M.; Wang, Z.; She, Z.; Hu, B.; Wang, Y.; Zhao, C. Comparison of physicochemical parameters during the forced-aeration composting of sewage sludge and maize straw at different initial C/N ratios. J. Air Waste Manag. Assoc. 2013, 63, 1130-1136. [CrossRef]

6. Domingo, J.L.; Nadal, M. Domestic waste composting facilities: A review of human health risks. Environ. Int. 2009, 35, 382-389. [CrossRef]

7. Yang, F.; Li, G.; Yang, Q.; Luo, W. Effect of bulking agents on maturity and gaseous emissions during kitchen waste composting. Chemosphere 2013, 93, 1393-1399. [CrossRef]

8. Jiang, T.; Schuchardt, F.; Li, G.; Guo, R.; Zhao, Y. Effect of C/N ratio, aeration rate and moisture content on ammonia and greenhouse gas emission during the composting. J. Environ. Sci. 2011, 23, 1754-1760. [CrossRef]

9. Zang, B.; Li, S.; Michel, F.; Li, G.; Luo, Y.; Zhang, D.; Li, Y. Effects of mix ratio, moisture content and aeration rate on sulfur odor emissions during pig manure composting. Waste Manag. 2016, 56, 498-505. [CrossRef]

10. Pagans, E.; Barrena, R.; Font, X.; Sanchez, A. Ammonia emissions from the composting of different organic wastes. Dependency on process temperature. Chemosphere 2006, 62, 1534-1542. [CrossRef]

11. Drennan, M.F.; Distefano, T.D. Characterization of the curing process from high-solids anaerobic digestion. Bioresour. Technol. 2010, 101, 537-544. [CrossRef]

12. Wu, T.; Wang, X.; Li, D.; Yi, Z. Emission of volatile organic sulfur compounds (VOSCs) during aerobic decomposition of food wastes. Atmos. Environ. 2010, 44, 5065-5071. [CrossRef]

13. Zhang, H.; Schuchardt, F.; Li, G.; Yang, J.; Yang, Q. Emission of volatile sulfur compounds during composting of municipal solid waste (MSW). Waste Manag. 2013, 33, 957-963. [CrossRef]

14. Toledo, M.; Marquez, P.; Siles, J.; Chica, A.; Martin, M. Co-composting of sewage sludge and eggplant waste at full scale: Feasibility study to valorize eggplant waste and minimize the odoriferous impact of sewage sludge. J. Environ. Manag. 2019, 247, 205-213. [CrossRef]

15. Zhou, J.-M. The Effect of Different C/N Ratios on the Composting of Pig Manure and Edible Fungus Residue with Rice Bran. Compos. Sci. Util. 2016, 25, 120-129. [CrossRef]

16. Yuan, J.; Li, Y.; Wang, G.; Zhang, D.; Shen, Y.; Ma, R.; Li, D.; Li, S.; Li, G. Biodrying performance and combustion characteristics related to bulking agent amendments during kitchen waste biodrying. Bioresour. Technol. 2019, 284, 56-64. [CrossRef]

17. Jolanun, B.; Towprayoon, S.; Chiemchaisri, C. Aeration improvement in fed batch composting of vegetable and fruit wastes. Environ. Prog. 2008, 27, 250-256. [CrossRef]

18. Toledo, M.; Gutierrez, M.C.; Siles, J.A.; Martin, M.A. Full-scale composting of sewage sludge and market waste: Stability monitoring and odor dispersion modeling. Environ. Res. 2018, 167, 739-750. [CrossRef]

19. Masó, M.; Blasi, A.B. Evaluation of composting as a strategy for managing organic wastes from a municipal market in Nicaragua. Bioresour. Technol. 2008, 99, 5120-5124. [CrossRef]

20. Wang, G.; Kong, Y.; Liu, Y.; Li, D.; Zhang, X.; Yuan, J.; Li, G. Evolution of phytotoxicity during the active phase of co-composting of chicken manure, tobacco powder and mushroom substrate. Waste Manag. 2020, 114, 25-32. [CrossRef]

21. Sellami, F.; Hachicha, S.; Chtourou, M.; Medhioub, K.; Ammar, E. Maturity assessment of composted olive mill wastes using UV spectra and humification parameters. Bioresour. Technol. 2008, 99, 6900-6907. [CrossRef]

22. Lin, C. A negative-pressure aeration system for composting food wastes. Bioresour. Technol. 2008, 99, 7651-7656. [CrossRef]

23. Huang, G.F.; Wu, Q.T.; Wong, J.C.; Nagar, B.B. Transformation of organic matter during co-composting of pig manure with sawdust. Bioresour. Technol. 2006, 97, 1834-1842. [CrossRef]

24. Yuan, J.; Chadwick, D.; Zhang, D.; Li, G.; Chen, S.; Luo, W.; Du, L.; He, S.; Peng, S. Effects of aeration rate on maturity and gaseous emissions during sewage sludge composting. Waste Manag. 2016, 56, 403-410. [CrossRef]

25. Neyla, S.; Soulwene, K.; Fadhel, M.; Naceur, J.; Meriam, M.; Abdennaceur, H.; Hadda, O. Microbiological parameters and maturity degree during composting of Posidonia oceanica residues mixed with vegetable wastes in semi-arid pedo-climatic condition. $J$. Environ. Sci. 2009, 21, 1452-1458.

26. Dhar, B.R.; Youssef, E.; Nakhla, G.; Ray, M.B. Pretreatment of municipal waste activated sludge for volatile sulfur compounds control in anaerobic digestion. Bioresour. Technol. 2011, 102, 3776-3782. [CrossRef]

27. Toledo, M.; Gutierrez, M.C.; Pena, A.; Siles, J.A.; Martin, M.A. Co-composting of chicken manure, alperujo, olive leaves/pruning and cereal straw at full-scale: Compost quality assessment and odour emission. Process Saf. Environ. Prot. 2020, 139, 362-370. [CrossRef] 